\title{
Do qualificar ao empreender: políticas de trabalho para jovens no Brasil
}

\author{
LIVIA DE TOMMASI ${ }^{I}$
}

e MARIA CARLA CORROCHANO ${ }^{I I}$

\section{Introdução}

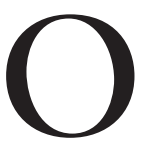
TRABALHO é uma das dimensões constitutivas da experiência juvenil brasileira. ${ }^{1}$ Ainda que os dados mais recentes evidenciem alterações na importância relativa de escola e trabalho nas duas últimas décadas, com ampliação significativa da presença do sistema educacional entre as jovens gerações, o trabalho e a busca por trabalho são realidades presentes nas trajetórias de um conjunto significativo deles e delas: $38,1 \%$ dos jovens brasileiros entre 15 e 29 anos trabalhavam e 11,6\% estudavam e trabalhavam no Brasil em 2019, sendo essa presença ainda mais intensa a partir dos 18 anos, para jovens de todos os segmentos sociais² (Brasil, 2019).

Ao final dos anos 1990, em um livro que se tornou referência para os estudos da área, Felícia Madeira (1998) escrevia um artigo intitulado "Recado dos jovens: mais qualificação", onde enfatizava a importância da elevação da escolaridade e da qualificação profissional para o enfrentamento dos desafios apresentados pelas novas configurações do trabalho. De fato, a qualificação ganhava centralidade como política de enfrentamento ao desemprego estrutural no mercado de trabalho brasileiro, até o início dos anos 2000. A mesma autora chamava a atenção para a relevância do trabalho na vida dos jovens (Madeira, 1998), mas, a despeito disso, foram tímidas as ações na esfera laboral. Mesmo no contexto de crescimento econômico e expansão do assalariamento vivido até 2014 , as ações dirigidas aos jovens permaneceram focalizando a dimensão da educação, o que segue sendo importante em um país onde a expansão das oportunidades educacionais aconteceu com bastante atraso (Ribeiro; Ceneviva; Brito, 2015 ).

Comentando os dados da pesquisa "Perfil da juventude brasileira", que revelava a centralidade do trabalho na vida dos jovens brasileiros, citado em segundo lugar entre as principais preocupações dos jovens, Sposito (2005, p.124) reforçava o chamado à atenção de Madeira anos depois, afirmando que "no Brasil, o trabalho também faz juventude".

Dar destaque para essa centralidade, argumentando que suas motivações não dizem respeito somente à necessidade de complementar a renda familiar, 
mas também a uma busca legítima pela autonomia dos jovens, nunca foi tarefa fácil no debate sobre direitos juvenis (Madeira, 1998; Guimarães, 2005; Corrochano, 2012). Assim como não foi olhar para os problemas ligados ao mundo do trabalho, tanto no que diz respeito à sua ausência (os índices de desemprego entre os jovens sempre são sensivelmente maiores do que entre a população em geral), ou presença como trabalho informal, mal remunerado, de baixa qualificação, como, ainda, com respeito ao cotidiano dos jovens, especialmente a necessidade de conciliar estudos, trabalho e vida familiar (Vargas; de Paula, 2012).

Postergar a entrada dos jovens no mundo do trabalho, privilegiando a elevação da escolaridade que permitiria ingressar no mercado mais bem qualificados, foi o leimotiv das políticas públicas dirigidas a esse segmento populacional, nos últimos vinte anos. Foram também ausentes as preocupações com o fato de que a expansão do Ensino Superior, permitindo a entrada de uma população até então excluída desse nível educacional, em especial negros e indígenas (Ribeiro; Schlegel, 2015), implicaria o aumento do contingente de jovens que estudam e ao mesmo tempo trabalham. Essa é a situação de $44 \%$ dos jovens cursando o Ensino Superior em 2019, alcançando quase 2,3 milhões de estudantes trabalhadores (Brasil, 2019).

Esse contingente de jovens trabalha geralmente em condições precárias, com jornadas longas e sem direitos; de acordo com os dados da PNAD Continua para 2019 , podemos estimar em $49,4 \%$ a proporção de jovens trabalhando na informalidade, com apenas $28,4 \%$ inseridos no mercado formal de trabalho. Tentando abordar essa problemática, o escritório da Organização Internacional do Trabalho (OIT) no Brasil empreendeu um esforço para definir os delineamentos do trabalho digno para os jovens, a partir de 2009. A construção de uma Agenda de Trabalho Decente para a Juventude no Brasil chamou a atenção para as necessárias políticas no campo da educação, e também do trabalho. Entretanto, sua concretização na forma de um Plano foi explicitamente barrada pela falta de consenso entre os atores, especialmente pela postura das representações empresariais em oposição aos avanços previstos (Corrochano, Abramo, H. Abramo, L., 2017 ).

O que se pode dizer do atual contexto, marcado pelo baixo crescimento econômico e por altas taxas de desemprego, subocupação e desalento que desde 2015 se avolumam, atingindo intensamente as gerações mais jovens? A taxa de desocupação entre os jovens de 15 a 29 anos no Brasil salta de 13,1\% em 2012 para 16,1\% em 2015, escalando para 22,2\% em 2019 (Brasil, 2019); nesse contexto se fortalece ainda mais o empreendedorismo, como saída para a falta de trabalho.

No auge da pandemia da Covid-19 no Brasil, são vários os diagnósticos que apontam para o aprofundamento da crise econômica e a necessidade de construção de respostas. Um dos grupos mais afetados pela crise é justamente aquele constituído pelos trabalhadores que empreendem. Estamos, portanto, num momento emblemático para refletir e problematizar sobre essa questão. 
Percorrer a trajetória das políticas e iniciativas que abordam a relação dos jovens com o trabalho no Brasil, nos últimos trinta anos, é o objetivo deste texto, tanto no que diz respeito às principais propostas de governo (governo federal e governo municipal em São Paulo) como às intervenções das fundações empresariais que têm tido, nesse âmbito, um protagonismo crescente. Não se trata aqui de recuperar o conjunto de ações e programas ou de avaliar a realidade da efetivação das políticas, mas por meio da descrição de algumas ações e programas, analisar as principais tendências no campo das ações públicas dirigidas a jovens no campo do trabalho.

\section{A centralidade da educação}

\section{e a inserção juvenil no mercado de trabalho}

Tanto as medidas governamentais direcionadas à geração de trabalho e renda, ${ }^{3}$ ao combate ao desemprego e à proteção para desempregados, quanto as ações públicas dirigidas a jovens ganham impulso a partir da década de 1990 no Brasil, com avanços limitados na década seguinte (Sposito; Carrano, 2003; Sposito, 2007; Rua, 1998). Nesse contexto, a tematização do trabalho juvenil foi marcada pelo desemprego, pela informalidade e precariedade do trabalho, experiências vividas de maneira dramática pelos jovens, em especial pelos segmentos historicamente afetados pela desigualdade, como as jovens mulheres, os jovens pobres, os negros (OIT, 1999).

A transformação do desemprego em problema estrutural, assim como o aumento da informalidade e a queda na renda do trabalho se relacionam a intensas mudanças na economia (Dedecca, 2003; Mattoso; Baltar, 1996). Esse movimento começa com a crise do padrão de desenvolvimento forjado no pós-guerra, levando a uma alteração no paradigma de expansão do assalariamento e dos direitos associados ao trabalho (Castel, 1998; Boltansky; Chiapello, 2009).

É nesse contexto que a "inserção juvenil" ou a "transição escola-trabalho" se transformam em problema político, na medida em que se interrompe a passagem entre a escola e o mundo do trabalho (Dubar, 2001). Embora de caráter estrutural, essas tendências precisam ser consideradas tanto a partir das especificidades de nosso país, como a informalidade, quanto pela correlação de forças entre os diferentes atores sociais e sua repercussão sobre o mundo do trabalho (Leite; Silva; Guimarães, 2017). Em relação aos jovens, o trabalho, antes mesmo da idade legal, e a combinação trabalho e estudos sempre estiveram presentes aqui, conformando outro padrão de transição (Hasenbalg, 2003).

Nos dois mandatos presidenciais de Fernando Henrique Cardoso (19952002) assistiu-se a algumas inovações nas políticas de geração de trabalho e renda, com a ampliação do seguro-desemprego e da capacitação profissional (Draibe, 2003). Nesse período as políticas de qualificação profissional foram centrais, em especial a partir do Plano Nacional de Qualificação Profissional (Planfor) que buscava ampliar a escolaridade de grupos específicos, articulando formação básica e formação profissional. ${ }^{4}$ Embora não destinado especificamente a jovens, 
o Plano tinha como público prioritário os trabalhadores na faixa de 15 a 30 anos, de baixa escolaridade, especialmente aqueles em "conflito com a lei" e os "excluídos" em geral (Piola; Pereira, 1998, p.12). Apesar de sua abrangência, o Planfor foi sujeito a um conjunto importante de críticas, a começar pelo diagnóstico sobre o desencontro entre o tipo de emprego gerado pelas mudanças tecnológicas e organizacionais no mundo do trabalho e a baixa qualificação dos trabalhadores (Franzói, 2003).

$\mathrm{O}$ "fetiche da capacitação do jovem para um mercado de trabalho de poucas oportunidades" (Sposito; Carrano, 2003, p.71) também aparece em outros programas, como o Agente Jovem de Desenvolvimento Social e Humano, e o Capacitação Solidária. A qualificação profissional aparece como promessa de empregabilidade, ao mesmo tempo que a noção de competência, forjada no ambiente empresarial ganha força (Hirata, 1994). No contexto da acumulação flexível, onde o controle seria realizado por objetivos e resultados, para além de conhecimentos formais, caberia aos trabalhadores apresentar habilidades " $\operatorname{cog}$ nitivas e comportamentais, tais como iniciativa, responsabilidade, autonomia, criatividade, cooperação, liderança, flexibilidade etc., para lidar com tarefas cada vez mais abstratas e complexas" (Tartuce, 2004, p.356).

O município de São Paulo destacou-se na construção de uma estratégia própria. No entanto, o Programa Bolsa Trabalho (PBT), criado pela Secretaria do Desenvolvimento, Trabalho e Solidariedade na gestão de Marta Suplicy (2001-2004), é outro exemplo de priorização da educação como resposta à situação desfavorável dos jovens no mercado de trabalho. Seguindo experiências de países como a França (Prefeitura, 2001, p.6), onde a permanência na escola se constituía como enfrentamento do desemprego juvenil (Lada, 2005), não deveriam ser introduzidos incentivos à inserção, mas estratégias voltadas à ampliação da escolaridade, postergando-se o ingresso dos jovens no mercado de trabalho. A transferência de renda assumiria um lugar central no Programa, na medida em que operava de modo compensatório em face da ausência de renda do trabalho.

O Programa dirigiu-se inicialmente a jovens entre 16 e 20 anos, estudantes ou concluintes do Ensino Médio, desempregados por mais de seis meses ou sem atividade remunerada, moradores de São Paulo nos dois últimos anos e vivendo em famílias com renda familiar igual ou inferior a dois salários mínimos por pessoa. Os participantes receberiam uma bolsa correspondente a $45 \%$ do salário mínimo por até dois anos. Simultaneamente, deveriam realizar algum tipo de formação complementar, que não precisava estar voltada para uma ocupação concreta no mercado de trabalho. O recebimento da bolsa estava condicionado à permanência na escola e à formação complementar, a semelhança de outros programas que se desenhavam em nível federal (Sposito; Corrochano, 2005). Ao analisar as trajetórias daqueles que participaram do programa, Corrochano (2012) identifica que esse teve sentidos diversos para os jovens, a depender de suas trajetórias escolares e profissionais, gênero e posição na família, mas o trabalho permanecia no centro de suas atenções. 
A construção de um amplo programa nacional destinado a enfrentar a situação desfavorável dos jovens no mercado de trabalho aconteceu apenas em 2003, com a criação do Programa Nacional de Estímulo ao Primeiro Emprego (PNPE), nos governos Luiz Inácio Lula da Silva (2003-2010). O programa tinha como objetivo a geração de postos de trabalho para jovens, e várias linhas de ação, dentre elas a subvenção econômica, os consórcios sociais da juventude, a juventude cidadã, o empreendedorismo e a responsabilidade social, bem como ações voltadas para a aprendizagem. Dirigia-se aos jovens entre 16 e 24 anos, desempregados e sem vínculo empregatício anterior, além de integrar jovens pertencentes a famílias com renda per capita de até meio salário mínimo, e frequentando a escola (Constanzi, 2009).

A oferta de incentivos econômicos às empresas constituiu-se num dos eixos centrais desse programa. No entanto, a subvenção foi encerrada em 2007 e o programa passou a privilegiar ações de qualificação profissional. Segundo Constanzi (2009) não há uma avaliação aprofundada das razões para essa mudança, mas emergem algumas hipóteses: a baixa qualificação dos jovens que se inscreviam no programa dificultava sua contratação; a falta de mecanismos adequados para formalizar a contratação de um jovem do programa. O autor também chama a atenção para os riscos desse programa, em especial a substituição de trabalhadores adultos por trabalhadores jovens, ou a ineficácia da política em si, uma vez que apostaria na redução do custo de um trabalhador que já apresenta baixos custos para a empresa.

No âmbito do PNPE a proposta que teve mais ressonância entre os jovens foi a dos Consórcios Sociais da Juventude, que tinha, para além de ações de qualificação e elevação da escolaridade, ações específicas voltadas para inserção. $\mathrm{O}$ programa priorizava jovens entre 16 e 24 anos, quilombolas, afrodescendentes, indígenas, jovem em conflito com a lei ou que estivessem cumprindo medidas socioeducativas, portadores de necessidades especiais e jovens trabalhadores rurais. A matrícula na escola também era condicionante para acesso ao Programa, além dos cursos de qualificação profissional e dos serviços voluntários.

Cardoso e Gonzáles (2007) evidenciam que as metas de inserção estabelecidas pelos Consórcios, sem recursos específicos, desconsiderando o perfil dos jovens e a dinâmica do mercado local, além da pouca preocupação com a qualidade das ocupações, foram pontos frágeis do Programa. A falta de articulação com políticas educacionais, profissionalizantes e laborais estruturantes acabou reforçando o encontro entre uma formação profissional ruim e um primeiro emprego precário.

Posteriormente ao PNPE, um dos programas que mais ganharam visibilidade foi o Programa Nacional de Inclusão do Jovem (Projovem), em 2005. Tinha como objetivo central a elevação da escolaridade e o estímulo à conclusão do Ensino Fundamental, qualificação profissional e ações comunitárias. O público-alvo era jovens entre 18 e 24 anos, com quatro a sete anos de escolaridade e 
sem vínculo empregatício, moradores de capitais e regiões metropolitanas com mais de duzentos mil habitantes. Aqui também havia concessão de bolsa por 12 meses no valor de R\$100,00 condicionada à frequência de 75\% nas atividades. O Programa passou por várias reformulações e em 2008 passou a chamar-se Programa Integrado da Juventude, incorporando diferentes programas até então existentes, ampliando a faixa de idade atendida para até 29 anos e o tempo de duração. Há um conjunto expressivo de avaliações em relação ao Programa destacando, dentre outros aspectos, sua dificuldade em responder à demanda de qualificação profissional entre os jovens.

Ainda que não direcionado especificamente ao público juvenil, vale mencionar o Programa Nacional de Acesso ao Ensino Técnico e Emprego (Pronatec). Criado em 2011, seu objetivo era ampliar a oferta de cursos de Educação Profissional e Tecnológica (EPT), por meio de programas de assistência técnica e financeira. A despeito de ser um esforço para diminuir a fragmentação das ações no campo da educação profissional, evidencia-se que o programa se aproxima do antigo Planfor, ao apoiar-se nos mesmos pressupostos para responder à "urgência de preparação para o mercado de trabalho". O programa estabelece relação linear entre formação e inserção no mercado de trabalho, cursos de formação rápidos e uma articulação estreita entre setor público e privado, com significativa participação do Sistema $S$. Embora contemple a expansão da rede federal de educação profissional e tecnológica, a maior oferta de vagas concentra-se nos curso de formação inicial e continuada, pouco articulados com a elevação da escolaridade. A ênfase ao Pronatec em detrimento de uma experiência de educação profissional que vinha se consolidando na rede federal, tal como o Programa Nacional de Integração da Educação Profissional com a Educação Básica na modalidade de Educação de Jovens e Adultos (Proeja) é avaliada como um retrocesso nas políticas de formação, além de claro sinalizador do recrudescimento das disputas políticas no interior da gestão, na medida em que busca atender interesses de grupos empresariais específicos (Franzói, 2013, Moraes, 2013).

Os investimentos no campo da saúde, educação e proteção social, além da geração de empregos formais e transferência de renda, foram importantes para a queda das desigualdades nos governos Lula e Dilma (Comin, 2015). As alterações no mercado de trabalho produziram impacto positivo nos indicadores de inserção juvenil: entre 2006 e 2013 houve uma redução de 15,6\% para 13\% na taxa de desemprego entre jovens de 15 e 29 anos, e de $52,1 \%$ para 38,6\% na informalidade (OIT, 2016). Também pode-se destacar a centralidade da qualificação profissional como direito e instrumento indispensável para inclusão e permanência no mundo do trabalho (Moraes, 2013). No entanto, o olhar para os programas aqui destacados evidencia a permanência de ações focalizadas nos jovens ditos "vulneráveis" e que, por seu caráter compensatório, avançam pouco em termos de garantia de direitos, ainda que possuam algum efeito em termos de socialização e educação cidadã. Soma-se a isso a frágil articulação com as políticas educacionais e com o Sistema Público de Trabalho, Emprego e Renda (Constanzi, 2009). 
Ainda que o Estatuto da Juventude reconheça o direito “à profissionalização, ao trabalho e à renda, exercido em condições de liberdade, equidade e segurança, adequadamente remunerado e com proteção social" (artigo 14), os programas não respondem aos desafios vividos pelos jovens.

Um dos avanços no direito ao trabalho foi a formulação da Agenda e do Plano Nacional de Trabalho Decente para a Juventude, entre 2010 e 2015, com apoio técnico da OIT. A Agenda enfatiza o lugar e a importância da busca por uma trajetória de desenvolvimento social e econômico que ofereça condições de vida dignas, mas evidencia o quanto são necessárias ações para além da educação e da qualificação profissional na esfera laboral. Ao estabelecer como suas prioridades os lemas de "mais e melhor educação", "conciliação dos estudos, trabalho e vida familiar", "inserção ativa e digna no mundo do trabalho", e o "diálogo social", a Agenda reconhece a necessidade de um conjunto integrado e complexo de ações ausentes nos programas vigentes (Brasil, 2010).

A Agenda previa uma série de ações relativas à formalidade do emprego, salário, saúde e segurança no trabalho, contrato e proteção social, direito à sindicalização. Contribuía, portanto, para romper a polarização que vinha se configurando nas ações destinadas aos jovens - ora estimular a elevação da escolaridade e a qualificação com intuito de adiar o ingresso no mundo do trabalho, ora estimular a inserção no trabalho, muitas vezes em ocupações precárias (Corrochano e Abramo, 2015; Corrochano; Abramo; Abramo, 2017).

Os avanços contidos na Agenda não se realizaram. A construção de um Plano que poderia dar mais concretude às suas diretrizes, incluindo a produção de indicadores e metas, revelou um conjunto de conflitos e tensões entre os atores ali presentes - organizações sindicais e de empregadores, gestores públicos, sociedade civil. A dificuldade para construir consensos em torno de questões cruciais, como jornada de trabalho, combate à informalidade, qualidade da educação e do trabalho, ou mesmo à situação dos jovens que não estudam e não trabalham impediu a aprovação do Plano, diante do jogo de forças presente entre os atores, na conjuntura de 2015 e 2016, às vésperas do impeachment de Dilma Rousseff.

\section{A aposta no empreendedorismo}

No período mais recente, enquanto desaparecem os programas voltados a promover a inserção dos jovens no mercado de trabalho formal, há uma significativa e crescente difusão de iniciativas voltadas a incentivar e celebrar o empreendedorismo (Tommasi, 2018).

Segundo a pesquisa GEM, ${ }^{5}$ que registra o aumento do número de jovens empreendedores no país, o percentual de empreendedores na faixa etária entre 18 e 24 anos estaria aumentando constantemente desde o ano 2000 até chegar, em 2018, a 22,2\% do total. ${ }^{6}$ De acordo com o Serviço Brasileiro de Apoio às Micro e Pequenas Empresas (Sebrae): “o jovem brasileiro já entendeu que para ter trabalho a melhor alternativa é criar o próprio emprego, é empreender, inovar e gerar novas vagas. E eles não empreendem por necessidade, estão de olho nas 
oportunidades do mercado, estão atendendo demandas sociais e movimentando a economia"?

A expansão na proporção de jovens empreendedores, registrada em anos recentes pelas pesquisas GEM, deve ser lida como resultado de investimentos anteriores na formação e no estímulo ao empreendedorismo, por meio, inclusive, da definição de suportes legais e institucionais. Investimentos diversos, impetrados por agentes e meios diversos, públicos e privados. ${ }^{8}$

Aponta o relatório GEM de 2007 que são as transformações no mundo do trabalho que tornam a atitude empreendedora um atributo necessário para qualquer trabalhador, mesmo para os que trabalham no setor formal. "Os empregos estão migrando de setor. No Brasil, em 1970, segundo o IBGE, a maioria dos empregos do país estava na indústria. Hoje, segundo a PNAD 2006, esse índice é pouco superior a $14 \%$. É um novo modelo de emprego que surge: o empreendedorismo. É difícil sobreviver na sociedade globalizada fora desse modelo" (GEM, 2008, p.86-7).

O diagnóstico proposto no relatório argumenta que, no país, não há um clima favorável à difusão do empreendedorismo, tanto pela formação escolar que privilegia a perspectiva da inserção laboral em relações de dependência, em consonância com as expectativas das famílias, como pela falta de suporte institucional, especificamente assessoria, formação e créditos. São essas carências que, sobretudo a partir dos anos 2010, programas públicos e privados vão tentar preencher, inclusive com uma vasta oferta de créditos bancários especificamente dirigidos à população de baixa renda. O Sebrae terá um papel central, tanto na promoção da formalização de empreendimentos como na oferta formativa, inclusive intervindo na formação escolar. ${ }^{9}$

A iniciativa que teve o maior impacto na produção de uma importante expansão do número de empreendimentos, graças, inclusive, à formalização dos trabalhadores informais que a legislação visava estimular, foi a promulgação de uma legislação voltada a favorecer a abertura de pequenos negócios via registro como o Micro Empreendedor Individual (MEI). ${ }^{10}$

O empreendedorismo se tornou uma matéria de estudo nas escolas, do Fundamental ao Ensino Médio, nas Universidades, na formação de professores e em cursos específicos das faculdades de administração e economia. A relevância do tema no âmbito da formação é corroborada pela existência de uma consistente produção acadêmica na área da educação (Pandolfi; Lopes, 2013).

André Gorz (2004), no livro intitulado O imaterial (publicado em França em 2003) explora as transformações ocorridas no mundo do trabalho que requerem outro tipo de trabalhador.

Essa é uma das grandes diferenças entre os trabalhadores de manufaturas ou de indústrias taylorizadas e aqueles do pós-fordismo. Os primeiros só se tomam operacionais depois de serem despojados dos saberes, das habilidades e dos hábitos desenvolvidos pela cultura do cotidiano e submetidos 
a uma divisão parcelada do trabalho. [...] Os trabalhadores pós-fordistas, ao contrário, devem entrar no processo de produção com toda a bagagem cultural que eles adquiriram nos jogos, nos esportes de equipe, nas lutas, disputas, nas atividades musicais, teatrais, etc. É nessas atividades fora do trabalho que são desenvolvidas sua vivacidade, sua capacidade de improvisação, de cooperação. (Gorz, 2004, p.19)

O trabalhador não é mais uma força de trabalho heterodirigida, mas deve investir permanentemente na produção de si, na aquisição de capacidade e competências necessárias para ter sucesso como trabalhador/empreendedor. É a teoria do capital humano que permeia, de forma significativa, a formação das novas gerações a partir dos anos 1990. A formação por competências, que comentamos ante, responderia a essa necessidade.

Portanto, não são somente os números sobre a quantidade de empreendedores (jovens e não) que operam no mercado brasileiro que importam. Se em tempos de crise o empreendedorismo aparece como uma saída ao aumento do desemprego, antes disso o empreendedor é um tipo de personalidade, um modo de produção de si. Isso afeta, em particular, as novas gerações. Ser empreendedor em qualquer âmbito da vida significa ter uma atitude proativa, ter iniciativa, não subir passivamente os percalços da vida e sim correr atrás, se ativar, ser propositivo na busca pela melhoria das próprias condições de vida, se responsabilizando pelos próprios sucessos ou fracassos.

A primeira iniciativa de envergadura de formação ao empreendedorismo introduzida no Brasil é o Seminário Empretec, um programa da Conferência das Nações Unidas para o Comércio e o Desenvolvimento (Unctad), realizado nos países em desenvolvimento desde 1985; no Brasil, é executado pela Unidade de Educação e Desenvolvimento da Cultura Empreendedora do Sebrae, que organiza o curso desde 1999. Melo (2008, p.99) percorre a história da atuação do Sebrae, analisando especificamente o seminário Empretec como ferramenta privilegiada de formação ao empreendedorismo; a metodologia utilizada nessa formação fornece, segundo ela, um modelo para as outras propostas formativas desenvolvidas pelo Sebrae para favorecer a difusão dos pequenos negócios.

Natália Melo (2008, p.74) argumenta que a proposta formativa do Empretec se baseia nas pesquisas desenvolvidas pelo psicólogo David McClelland, que a partir dos anos 1960 indaga as características da motivação para a realização pessoal e social. O Empretec se propõe desenvolver motivação e promover mudanças comportamentais que favoreçam o sucesso nos negócios. Para isso, nada melhor do que o exemplo; papel central, na formação empreendedora, é o dos "gurus" que motivam, incentivam, mostram com seu exemplo o caminho a percorrer para obter sucesso (ibidem, p.82). A função da educação empreendedora é facilitar o "conhecimento de si mesmo", promover uma "viagem interior", ou ainda, um "processo de perceber sua vocação" (ibidem, p.110). A força motriz da ação empreendedora é a necessidade de realização das pessoas. 
Resumindo seu trabalho, Melo (2008, p.VI) frisa que o Empretec "constitui-se de um treinamento comportamental que visa transformar a conduta dos indivíduos. O empreendedorismo, assim, se apresenta não como conceito acadêmico de valor descritivo, mas sim, como um conjunto prescritivo de normas e valores que orientam e alteram a percepção dos indivíduos".

Num texto escrito em 1998 Nikolas Rose discute a conformação da subjetividade empreendedora como uma estratégia de poder, fazendo referência à concepção de poder elaborada por Michel Foucault (1987, p.161), que concebe o poder em termos produtivos, "não como uma negação da vitalidade e das capacidades dos indivíduos, mas como a criação, modelagem e utilização dos seres humanos como sujeitos" (Rose, 2011, p.211). Rose (2011, p.215) argumenta:

$\mathrm{O}$ vocabulário do empreendedorismo une a retórica política e os programas regulatórios às capacidades de "autodireção" das pessoas. [...] Refere-se a uma série de regras para a conduta da existência diária de uma pessoa: energia, iniciativa, ambição, cálculo e responsabilidade pessoal. O self empreendedor fará da sua vida um empreendimento, procurando maximizar seu próprio capital humano, projetando seu futuro e buscando se moldar a fim de se tornar aquilo que deseja ser $[\ldots]$

Formar indivíduos, governar suas condutas é, portanto, mais importante do que, efetivamente, resolver o problema do desemprego. Problema que, em todo caso, pode ser gerido convencendo as pessoas de que elas são as únicas responsáveis por seu sucesso profissional; e que, para ter sucesso, é preciso, especialmente, mudar seu comportamento.

O setor privado teve, no campo da juventude, um papel relevante na difusão do empreendedorismo no decorrer dos anos 2000. Em 1999 três importantes instituições empresariais (Instituto Ayrton Senna, Fundação Kellogg, Instituto Odebrecht), além do Banco Nacional do Desenvolvimento (BNDES) lançam o programa "Aliança com o Adolescente pelo Desenvolvimento Sustentável no Nordeste", ativo em três estados da região. ${ }^{11}$ No âmbito do programa, os jovens participam do Seminário Empretec e são incentivados a abrir seu próprio empreendimento, econômico e/ou social, a ter uma atitude proativa não somente com relação a seu destino, mas, também, àquele de sua comunidade. Os jovens, considerados agentes de desenvolvimento local, são incentivados a elaborar e realizar projetos de intervenção para solucionar problemas sociais. A imagem do jovem como protagonista, agente de mudança, é contraposta àquela do jovem como problema social (Tommasi, 2014).

O Grupo de Institutos, Fundações e Empresas (Gife) em 2008 dedica a publicação de seu balanço anual ao tema da juventude, identificada como uma prioridade. A ativação da juventude em prol do desenvolvimento social é, para as empresas, parte do combate à pobreza e do enfrentamento da questão social; é parte do incentivo à inserção no mundo do trabalho: "Tal resultado confirma nossa visão de promover a população jovem ao protagonismo de ações sociais para seu próprio desenvolvimento e inserção no mundo do trabalho (Gife, 2008, p.9). 
Nos últimos anos, o setor empresarial abre mão de novas estratégias de enfrentamento da questão social. Ao paradigma do Terceiro setor e da "nova filantropia empresarial" dos anos 1990 (Jaime, 2005), que visava supostamente introduzir uma maior profissionalização das ações sociais, mediante a adoção dos modelos de eficácia e eficiência do setor empresarial, substitui-se a ideia de que produzir transformações sociais e produzir lucro não são objetivos antitéticos. Ao contrário, eles podem ser perseguidos concomitantemente pelos chamados negócios de impacto social. "A crença de que podemos gerar transformações por meio de soluções que aliam impacto socioambiental com um modelo de negócios rentável é o nosso ponto de partida." 12

Não se trata somente de fazer com que as "virtudes" (eficiência, eficácia, flexibilidade) do mercado contaminem a gestão do social (pública e não), mas de tornar o mercado o principal agente do social. No paradigma difuso atualmente pelo setor empresarial aliviar os problemas sociais, estimular o crescimento e movimentar o mercado podem e devem ir junto. À imagem do capitalismo predador se substitui a imagem do capitalismo como produtor do bem, da justiça, da paz social. As ações sociais devem se tornar mais efetivamente fontes de renda, tanto para os beneficiários como para os investidores (Jaime, 2005, p.961).

Responsável por ter introduzido o conceito de negócios de impacto social no Brasil é a organização Artemisia, cujo objetivo da instituição é apoiar "o desenvolvimento de talentos e empreendedores na criação e desenvolvimento de negócios de impacto que ajudam a resolver os problemas sociais da população de baixa renda no Brasil". ${ }^{13}$

O lema da Artemisia ("entre ganhar dinheiro e mudar o mundo fique com os dois") tem um grande apelo entre jovens. Inquietação, insatisfação com o trabalho formal, rebeldia contra o sistema são elementos que caracterizam a atuação de jovens envolvidos em coletivos culturais, atuação que tem crescido significativamente nas cidades brasileiras, e em particular em São Paulo, graças à difusão de editais de financiamento específicos como o programa de Valorização de Iniciativas Culturais de jovens (VAI). Entre esses jovens se difunde a ideia de que a criação de empreendimentos pode sustentar suas atividades, superando a dependência dos incertos financiamentos públicos (Campos, 2019; Silva, 2018). Virar empreendedor, abrir o próprio negócio para sustentar atividades coletivas, representa a possibilidade de fazer acontecer, preservando a autonomia, em linha com a ideia de "faça você mesmo" difusa entre os movimentos contraculturais desde os anos 1970 (Tommasi, 2018).

Nesse quadro, a formalização dos empreendimentos via registro como MEI tem sido um recurso importante. Virar empreendedor é uma possibilidade concreta, para muitos jovens, para construir para si uma alternativa ao desemprego, ao trabalho precário em mansões subalternas, para concretizar seus sonhos (Ferreira, 2017).

O empreendedorismo valoriza as atividades informais, os excluídos do mundo empresarial e do emprego formal. Os que sempre viveram "à margem" 
do sistema. Aliás, são justamente eles que, acostumados a se virar, a fazer da necessidade virtude, usando a criatividade para sobreviver na adversidade, são considerados potencialmente mais criativos, inovadores, ousados; ou seja, empreendedores. Mesmo se as condições objetivas dessas camadas sociais não se alterem profundamente, muda-se a forma como são vistas socialmente; ou, ao menos, esta possibilidade está ao alcance de qualquer um que se responsabilize pela sua própria mudança (Melo, 2008, p.121).

Esses fatores promovem a adesão ao empreendedorismo mesmo de segmentos sociais críticos com respeito à ordem dominante, como os jovens envolvidos em coletivos culturais periféricos (Campos, 2019; Silva, 2018; Tommasi, 2018) e as mulheres negras (Silva, 2017). Problematizar as consequências dessa disseminação, em particular entre jovens, significa pensar seus efeitos não somente em termos de difusão e aceitação das leis do mercado, mas também com relação à gestão do conflito social, num presente marcado pelo acirramento das desigualdades e a crise da democracia.

\section{Considerações finais}

Abrindo este texto tratamos da centralidade do trabalho na vida dos jovens. Apesar dessa centralidade, as propostas de políticas públicas foram bastante tímidas e, geralmente, focalizadas em segmentos específicos de jovens, aqueles considerados mais vulneráveis.

De início observamos que as intervenções do governo federal foram prioritariamente centradas na elevação da escolaridade e da qualificação profissional. De fato, no campo das políticas de geração de trabalho e renda, as ações de qualificação profissional sempre tiveram um peso maior, especialmente, ainda que não exclusivamente, em razão dos limites à geração de postos de trabalho em um cenário de baixo crescimento econômico. Mesmo no cenário de crescimento econômico a partir dos anos 2000, o foco na educação permaneceu, e essa parece ser uma escolha muito mais forte quando se trata das gerações mais jovens. Mas pudemos também constatar a ausência de uma política estrutural de emprego para a juventude, algo que caracteriza tanto os mandatos de FHC, como posteriormente de Lula e Dilma Rousseff.

Por seu turno, o tema do empreendedorismo passa a ocupar as agendas de organismos públicos e privados, sobretudo nos últimos dez anos. Para além da geração de ocupação e renda, a ênfase consiste em moldar um determinado tipo de personalidade, em tese ajustada ao espírito do capitalismo: concorrencial, individualista, focado na responsabilização das pessoas. Os jovens, enquanto "sujeitos em formação", receberam de forma mais significativa as investidas voltadas à difusão de uma cultura empreendedora.

A precarização das relações de trabalho se afirmou nos últimos anos no Brasil tanto por meio do ideário sobre o trabalho autônomo como pelas reformas que atingiram os direitos trabalhistas, golpeando de forma contundente todos aqueles que vivem do seu trabalho, incluindo e deixando sem perspectiva 
de inserção os jovens pobres, negros, moradores das periferias das grandes metrópoles.

Nesse quadro, o empreendedorismo pode ser considerado outra forma de precarização. O empreendedor deve assumir a responsabilidade pelo sucesso de seu produto ou serviço, "correr atrás" de todas as tarefas que decorrem do abastecimento, da produção, da venda, da comunicação, dos investimentos; deve conviver com as incertezas do mercado e precisa não sucumbir em tempos de recessão, doença ou percalços da vida. Assumir riscos, sem uma rede de suporte adequada, não poder saber com quanto dinheiro é possível contar, viver na incerteza e na precariedade. Cair na pobreza, no endividamento, na falta de amparo são riscos sempre presentes na vida dos empreendedores.

Estarão os jovens empreendedores, municiados para lutar por seus direitos? As críticas dirigidas ao ideário empreendedor (Machado da Silva, 2002) geralmente ressaltam as consequências da difusão da cultura empreendedora em termos de incentivo ao individualismo e entraves à organização coletivas. Mas as redes de solidariedade e apoio mútuo que hoje estão sendo organizadas nas periferias das grandes cidades, com a participação significativa de coletivos juvenis para garantir a sobrevivência das famílias nesse tempo de necessário distanciamento social, mostram que o saber-fazer empreendedor pode ser utilizado para superar o individualismo e a fragmentação.

\section{Notas}

l O artigo refere-se ao direito ao trabalho a partir dos 16 anos, idade mínima para admissão ao trabalho no Brasil e ao trabalho na condição de aprendiz a partir dos 14 anos, como estabelece a Lei de Aprendizagem (Lei n.10.097/2000). Cabe mencionar que uma parte das reflexões aqui produzidas estão relacionadas ao projeto: Coletiva Jovem: um projeto de pesquisa e ação para suporte aos coletivos juvenis de produção nas periferias de São Paulo e Buenos Aires, realizado com apoio da Fapesp (Processo n. 2018/ 12094-3).

2 Além de variar conforme as faixas de idade no período da juventude, a presença do trabalho e da escola também variam conforme renda familiar, sexo/gênero/ cor/ raça e local de moradia (Corrochano et al., 2008; Sposito; Souza; Arantes, 2018).

3 A abordagem conceitual precisa seria políticas de emprego. Nos países centrais do pós-guerra, em um cenário de crescimento econômico, pleno emprego e consolidação do Welfare State, os programas públicos que visavam à proteção do trabalhador (como seguro-desemprego, intermediação de trabalho e formação profissional) exerciam função acessória. Essa situação alterou-se em face da crise internacional dos anos 1970, quando as políticas acessórias acabaram por se transformar no núcleo central das políticas de emprego (Moretto et al., 2003).

4 Não se trata de realizar análise do conjunto das políticas no campo da educação, da educação profissional e do trabalho. No entanto, o Planfor relacionou-se a profundas mudanças nas orientações da educação média e profissional a partir do Decreto n.2.208/1997, levando, na perspectiva de diferentes análises, ao retrocesso ao dualismo estrutural entre ensino acadêmico e ensino técnico. Ver Moraes (1998). 
5 Considerada como a mais abrangente pesquisa sobre empreendedorismo no mundo, o Global Entrepreneurship Monitor (GEM) é executado no Brasil desde o ano 2000 pelo Instituto Brasileiro da Qualidade e Produtividade (IBQP), em parceria com o Sebrae. Na esfera internacional, o GEM é administrado por uma holding - Global Entrepreneurship Research Association, ligada às duas instituições fundadoras, a London Business School e o Babson College de Boston. Fonte: Disponível em: <http://www. ibqp.org.br/gem/objetivos/>. Acesso em: 25 fev. 2020.

6 Disponível em: <https://datasebrae.com.br/wp-content/uploads/2019/02/GEM2018-Apresenta\%C3\%A7\%C3\%A3o-SEBRAE-Final-slide.pdf>. Acesso em: 24 fev. 2020 .

7 Disponível em: <https://istoe.com.br/cresce-numero-de-jovens-empreendedores-no-brasil/>. Acesso em: 25 fev. 2020.

8 Para citar alguns, só no ano 2000 teve a adesão do Brasil ao sistema GEM, a criação do Encontro de Estudos sobre Empreendedorismo e Gestão de Pequenas Empresas (Egepe), principal evento científico da área, a constituição da Confederação Nacional dos Jovens Empresários (Conaje), entidade que tem como missão representar, aglutinar e informar jovens empresários, fomentando o empreendedorismo (Disponível em: <http://conaje.com.br/institucional/>. Acesso em: 6 maio 2020) que teve assento no Conselho Nacional de Juventude, criado em 2006.

9 O Programa de formação de jovens empreendedores, desenvolvido pelo Sebrae, tem como objetivo disseminar a cultura empreendedora nas escolas públicas e privadas de ensino médio (Dias, 2006).

10 A Lei Complementar n.128/2008 criou a figura do Microempreendedor Individual. A Medida Provisória (MP) n.529/2011 facilitou o acesso ao MEI, aumentando o valor da receita para elegibilidade e reduzindo a $5 \%$ a alíquota de contribuição ao INSS. Atualmente os MEI podem faturar até R\$ 81 mil por ano; têm CNPJ, acesso à Previdência Social, direito ao afastamento por motivos de saúde. Para um estudo sobre o impacto dessa legislação, ver Corseuil, Neri e Ulyssea (2014).

11 Disponível em: <www.institutoalianca.org.br>. Acesso em: 11 maio 2020.

12 Disponível em: <http://www.investirparatransformar.org.br/>. Acesso em: 3 mar. 2020.

13 Disponível em: <http://artemisia.org.br>. Acesso em: 3 mar. 2020.

\section{Referências}

BRASIL. Agenda Nacional de Trabalho Decente para a Juventude. Brasília: MTE, 2010. Pesquisa Nacional por Amostra de Domicilios Contínua. IBGE. 2019. Rio de

Janeiro: IBGE, 2019.

BOLTANSKI, L.; CHIAPELLO, E. O novo espirito do capitalismo. São Paulo: Martins Fontes, 2009.

CAMPOS, F. O. Cultura, Espaço e Politica: um estudo da Batalha da Matrix de São Bernardo do Campo. São Paulo, 2019. 221p. Dissertação (Mestrado em Estudos Culturais) - Programa de Pós-Graduação em Estudos Culturais, Universidade de São Paulo.

CARDOSO, J. C.; GONZÁLES, R. Desemprego juvenil e políticas de trabalho e renda 
no Brasil: a experiência recente dos Consórcios Sociais da Juventude. Inclusão Social, Brasília, v.2, n.1, p.30-46, out. 2006/mar. 2007.

CORROCHANO, M.C.; ABRAMO, H. W.; ABRAMO, L. O trabalho juvenil na agenda pública brasileira: avanços, tensões, limites. Revista Latino americana de Estudios del Trabajo. Buenos Aires: v. 22, n. 35, p. 135-169, jan. 2017.

CORROCHANO, M. C.; ABRAMO, L. Juventude, educação e trabalho decente. Linhas criticas (UnB), v.22, p.110-119, dez. 2016.

CORROCHANO, M. C. O trabalho e a sua ausência: narrativas juvenis na metrópole. São Paulo: Ed. Annablume/ Fapesp, 2012.

CORROCHANO, M. C. et al. Jovens e trabalho no Brasil: desigualdades e desafios para as políticas públicas. São Paulo: Ação Educativa, 2008.

CASTEL, R. As metamorfoses da questão social. Petrópolis: Vozes, 1998.

COMIN, A. Desenvolvimento econômico e desigualdades no Brasil: 1960-2010. In: Trajetórias das desigualdades: como o Brasil mudou nos últimos cinquenta anos. São Paulo: Editora Unesp; CEM, 2015. p.367-94.

CONSTANZI, R. G. Trabalho decente e juventude no Brasil. Brasília: Organização Internacional do Trabalho, 2009.

CORSEUIL, C. H. L.; NERI, M. C.; ULYSSEA, G. Uma análise exploratória dos efeitos da política de formalização dos microempreendedores individuais. Texto para Discussão, Brasília, Instituto de Pesquisa Econômica Aplicada, n.1939, 2014.

DEDECCA, C. S. Anos 90: estabilidade com desigualdade. In: PRONI, M. W.; HENRIQUE, W. (Org.) Trabalho, mercado e sociedade. São Paulo: Editora Unesp, 2003. p.71-106.

DIAS, G. P. Empreendedorismo e educação: o Sebrae na escola. Neterói, 2006. Dissertação (Mestrado em Educação) - Programa de Pós-Graduação em Educação, Universidade Federal Fluminense.

DUBAR, C. La construction sociale de l'insertion professionnel en France. In: ROULLEAU-BERGER, L.; GAUTHIER, M. (Org.) Les jeunes et l'emploi. Paris: Editions de l'Aube, 2001.

DRAIBE, S. A política social no período FHC e o sistema de proteção social. Tempo Social, São Paulo, v.15, n.2, p.63-102, nov. 2003.

FERREIRA, V. S. Ser DJ não é só soltar o play: a pedagogização de uma nova profissão de sonho. Educação \& Realidade, [s.1.], n.58, p.71-108, set. 2017.

FOUCAULT, M. Vigiar e punir. 10.ed. Petrópolis: Vozes, 1987.

FRANZÓI, N. Da profissão como profissão de fé ao "mercado em constante mutação": trajetórias e profissionalização dos alunos do Plano Estadual de Qualificação do Rio Grande do Sul (PEQ-RS). Campinas, 2003. 250p. Tese (Doutorado em Educação)

- Faculdade de Educação, Universidade Estadual de Campinas.

FRANZÓI, N. L. Proeja e Pronatec: ciclo de políticas, políticas recicladas. Políticas Educativas. Porto Alegre, v.6, n.2, p.84-100, 2013.

GEM. Empreendedorismo no Brasil 2007. Curitiba: IBQP, 2008.

GIFE. Censo GIFE Juventude. São Paulo, 2008. 
GORZ, A. O imaterial: conhecimento, valor e capital. São Paulo: Annablume, 2004.

GUIMARÃES, N. A. Trabalho: uma categoria-chave no imaginário juvenil? In: ABRAMO, H. W.; BRANCO, P. P. M. (Org.) Retratos da juventude brasileira: análises de uma pesquisa nacional. São Paulo: Fundação Perseu Abramo, 2005. p.149-74.

HASENBALG, C. A transição da escola ao mercado de trabalho. In: HASENBALG, C.; SILVA, N. V. Origens e destinos: desigualdades sociais ao longo da vida. Rio de Janeiro: Topbooks, 2003.

HIRATA, H. Da polarização das qualificações ao modelo da competência. In: FERRETTI, C. et al. (Org.) Novas tecnologias, trabalho e educação: um debate multidisciplinar. Rio de Janeiro: Vozes, 1994. p.124-44.

JAIME, P. O empresariado e a questão social: apontamentos para a interpretação de um novo associativismo empresarial no Brasil. Revista de Administração Pública, v.39, n.4, p.939-78, jul./ago, 2005.

LADA, E. Quand les marges deviennent centre: mise au travail, jeunesses populaires et rapports sociaux (de sexe) dans le secteur public et associatif. Saint-Quentin-en-Yvelines, 2005. Thèse (Doctorat en Sociologie) - U. F. R. de Sciences Sociales et Humaines, Université de Versailles.

LEITE, M. P.; SILVA, S.A.; GUIMARÃES. O trabalho na confecção em São Paulo: as novas formas da precariedade. Cadernos CRH, Salvador, v.30, n.79, p.51-68, jan./ abr. 2017.

MADEIRA, F. R. Recado dos jovens: mais qualificação. In: BRASIL. Ministério do Planejamento e Orçamento. Jovens acontecendo na trilha das politicas públicas. Brasília: CNPD, 1998. p.427-96.

MACHADO DA SILVA, L. A. Da Informalidade à Empregabilidade (reorganização a dominação no mundo do trabalho). Cadernos CRH, Salvador, n.37, 2002.

MATTOSO, J.; BALTAR, P. Transformações estruturais e emprego nos anos 90. Campinas: Unicamp-IE, 1996. (Cadernos do CESIT, n.21).

MELO, N. Sebrae e empreendedorismo: origens e desenvolvimento. São Carlos, 2008. Dissertação (Mestrado em Ciências Sociais) - Programa de Pós-Graduação em Ciências Sociais, Universidade Federal de São Carlos.

MORAES, C. S. V. A Reforma do Ensino Médio e a Educação Profissional. Trabalho e Educação, Revista do NETE (Núcleo de Estudos sobre Trabalho e Educação), FaE/ UFMG, p.97-115, jan./jul.1998.

Educação de jovens e adultos trabalhadores de qualidade: regime de colaboração e Sistema Nacional de Educação. Educação e Sociedade, Campinas, v.34, n.124, p.979-1001, jul.-set. 2013.

MORETTO, A. et al. Os descaminhos das políticas de emprego no Brasil. In: PRONI, M. W.; HENRIQUE, W. (Org.). Trabalho, mercado e sociedade. Campinas: Ed. Unesp, 2003. p. 231-278.

OIT - ORGANIZAÇÃO INTERNACIONAL DO TRABALHO. Plano Nacional do Trabalho Decente para a Juventude (PNTDJ). Documento preliminar. Brasília, OIT, 2016 / mimeo/.

OIT - ORGANIZAÇÃO INTERNACIONAL DO TRABALHO (Org.). Desemprego 
juvenil no Brasil: em busca de opções à luz de algumas experiências internacionais. Brasília: OIT, 1999.

PANDOLFI M. de A.; LOPES R. E.A educação voltada para o empreendedorismo: Um levantamento do debate acadêmico. Revista HISTEDBR On-line, Campinas, n.49, p.177-196, 2013.

PIOLA, S.; PEREIRA, R. Gasto social federal e gasto com jovens de 15 a 24 anos. In: BRASIL. Ministério do Planejamento e Orçamento. Jovens acontecendo na trilha das políticas públicas. Brasília: CNPD, 1998. p. 713-730.

PREFEITURA. Lei n.13.163, de 2001. Regulamentada pelo Decreto n.40.845, de 2001. Portal do Trabalho. Disponível em: <www.leismunicipais.com.br>. Acesso em: 21 set. 2007.

RIBEIRO. C.; SCHELEGEL, R. Estratificação horizontal da educação superior no Brasil (1960 a 2010). In: ARRETCHE, M. Trajetórias das desigualdades: como o Brasil mudou nos últimos cinquenta anos. São Paulo: Editora Unesp; CEM, 2015, p. 133162.

RIBEIRO, C. C.; CENEVIVA, R.; BRITO, M. M. A. Estratificação educacional entre jovens no Brasil. In: ARRETCHE, M. Trajetórias das desigualdades: como o Brasil mudou nos últimos cinquenta anos. São Paulo: Ed. Unesp; CEM, 2015, p.79-108

ROSE, N. Inventando nossos selfs: Psicologia, poder e subjetividade. Petrópolis: Vozes, 2011.

RUA, M. G. As políticas públicas e a juventude nos anos 90. In: BRASIL. Ministério do Planejamento e Orçamento. Jovens acontecendo na trilha das políticas públicas. Brasília: MPO, 1998. p.731-49.

SILVA, G. Empreendimentos sociais, negócios culturais: uma etnografia das relações entre economia e política a partir da Feira Preta em São Paulo. São Paulo, 2017. Tese (Doutorado em Antropologia) - Programa de Pós-Graduação em Antropologia, Universidade de São Paulo.

SILVA, G. M. Ocupação: cultura. Reflexões sobre sonho e trabalho. Niterói, 2018. Dissertação (Mestrado em Cultura e Territorialidades) - Universidade Federal Fluminense.

SPOSITO, M.; SOUZA, R.; SILVA, F.A. A pesquisa sobre jovens no Brasil: traçando novos desafios a partir de dados quantitativos. Educação e Pesquisa, [s.1.], v.44, p.1-24, dez. 2017.

SPOSITO, M. P. (Coord.). Espaços públicos e tempos juvenis: um estudo de ações do poder público em cidades de regiões metropolitanas brasileiras. São Paulo: Global, 2007

SPOSITO, M. P.; CORROCHANO, M. C. A face oculta da transferência de renda para jovens no Brasil. Tempo Social, São Paulo, v.17, n.2, p.141-172, nov. 2005.

SPOSITO, M. Algumas reflexões e muitas indagações sobre as relações entre juventude e escola no Brasil. In: ABRAMO, H. W.; BRANCO, P. P. M. (Org.). Retratos da juventude brasileira: análises de uma pesquisa nacional.São Paulo: Perseu Abramo, 2005.

SPOSITO, M. P.; CARRANO, P. Juventude e políticas públicas no Brasil. Revista Brasileira de Educação, São Paulo, n.24, p.16-39, set./dez. 2003.

TARTUCE, G. L. Algumas reflexões sobre a qualificação do trabalho a partir da sociologia francesa do pós-guerra. Educação e Sociedade, v. 25, n. 87, p. 353-382, maio/ago. 2004. 
TOMMASI, L. Juventude, projetos sociais, empreendedorismo e criatividade: dispositivos, artefatos e agentes para o governo da população jovem. Passagens. Revista Internacional de História Politica e Cultura Jurídica. Rio de Janeiro, v.6, n.2, p. 287-311, mai-ago., 2014.

. Empreendedorismo cultural nas margens da cidade, in: ROCHA, C. et. al. (Org.), Militarização no Rio de Janeiro: da pacificação à intervenção. Rio de Janeiro: Mérula, 2018.

VARGAS, H.; DE PAULA, M. F. C. A inclusão do estudante-trabalhador e do trabalhador-estudante na educação superior: desafio público a ser enfrentado. Avaliação, Campinas/Sorocaba, v.18, n.2, p.459-85, 2012.

RESUMO - O artigo aborda a trajetória das políticas e propostas que, nos últimos trinta anos, enfrentaram a especificidade da relação dos jovens com o trabalho no Brasil, tanto no que diz respeito às principais propostas de governo (especificamente, do governo federal e do governo municipal na cidade de São Paulo) quanto aquelas das fundações empresariais. Desde a ênfase sobre a qualificação profissional no início dos anos 1990, até a difusão recente da agenda do empreendedorismo, as mudanças acompanharam as transformações ocorridas no mundo do trabalho, no contexto de afirmação do "novo espírito do capitalismo". O enfraquecimento das garantias trabalhistas, a responsabilização do trabalhador, a ênfase sobre a assunção de riscos, a fragmentação e individualização são elementos centrais de novas formas de subjetivação que atingem, especificamente no caso brasileiro, os jovens pobres.

PALAVRAS-CHAVE: Juventude, Trabalho, Qualificação profissional, Empreendedorismo.

ABSTRACT - The article discusses the trajectory of policies and proposals that, in the last 30 years, dealt with the relationship of young people with work in Brazil, including both the main government proposals (specifically, the federal government and the municipal government of the city of São Paulo), and those of corporate foundations. From the emphasis on professional qualification in the early 1990s to the recent dissemination of an entrepreneurial agenda, the changes have accompanied the new work trends that emphasize a "new spirit of capitalism." The weakening of labor guarantees, worker accountability, emphasis on risk-taking, fragmentation and individualization are central elements of new forms of subjectification that, especially in the Brazilian case, affect underprivileged youth.

KEYWORDS: Youth, Work, Professional qualification, Entrepreneurship.

Livia de Tommasi é professora associada do curso de Bacharelado em Políticas Públicas e do Programa de Pós-Graduação em Ciências Humanas e Sociais da Universidade Federal do ABC. @- livia.detommasi@gmail.com /

http://orcid.org/0000-0003-1263-8354.

Maria Carla Corrochano é professora associada do Departamento de Ciências Humanas e Educação e dos Programas de Pós-Graduação em Educação e em Estudos da Condição Humana da Universidade Federal de São Carlos / Campus Sorocaba. @ - carla.corrochano@gmail.com / http://orcid.org/0000-0001-8030-6461.

Recebido em 11.5.2020 e aceito em 12.6.2020. 
I Programa de Pós-Graduação em Ciências Humanas e Sociais, Universidade Federal do ABC, Santo André, São Paulo, Brasil.

II Programas de Pós-Graduação em Educação e em Estudos da Condição Humana, Universidade Federal de São Carlos, Campus Sorocaba, São Paulo, Brasil. 
